\title{
Migraine: Prevalence and Associated Disability Among Nigerian Undergraduates
}

\author{
Kolawole Wasiu Wahab, Asuwemhe Johnson Ugheoke
}

\begin{abstract}
Background: Studies on migraine in Nigeria are scanty while the disability associated with the disease has not been determined. We aimed at determining the lifetime prevalence of migraine and its associated disability among the students of a Nigerian university. Method: Using a multi-stage sampling method, undergraduates of Ambrose Alli University, Nigeria were screened with the International Headache Society (IHS) criteria. Those who satisfied the criteria for migraine were then assessed with the Migraine Disability Assessment questionnaire to ascertain the level of disability resulting from migraine in the three months preceding the study. Information was also obtained on the use of preventive and abortive medications. Results: Out of the 1513 respondents screened, 145 satisfied the IHS criteria for the diagnosis of migraine giving an overall lifetime prevalence of $9.6 \%$ (females $10.3 \%$, males $8.9 \%$, $\mathrm{p}>0.05$ ). Migraine associated disability was little or none in $53.1 \%$ (males 55.2\%, females 51.3\%, p>0.05), mild in $10.3 \%$ (males $11.9 \%$, females $9.0 \%, \mathrm{p}>0.05$ ), moderate in $20.7 \%$ (males $20.9 \%$, females $20.5 \%$, p >0.05) and severe in $15.9 \%$ (males $11.9 \%$, females $19.2 \%$, $\mathrm{p}>0.05)$. In spite of the fact that $53(36.6 \%)$ of the migraineurs had moderate-severe disability, only 19/53 (35.8\%) reported being on preventive treatment while none had ever used a triptan. Conclusion: Prevalence of migraine among our respondents falls within the range reported from similar studies among university students outside Africa. In spite of the high disability associated with the disease, use of effective preventive and abortive therapies is very poor.
\end{abstract}

RÉSUMÉ: Prévalence de la migraine et de l'invalidité qui y est associée chez des étudiants sous-gradués au Nigeria. Contexte : Il existe peu d'études sur la migraine au Nigeria et l'invalidité associée à cette maladie n'a pas été déterminée. Notre but était de déterminer la prévalence à vie de la migraine et l'invalidité qui y est associée chez les étudiants d'une université nigérienne. Méthode : Les étudiants de l'Université Ambrose Alli au Nigeria ont été dépistés par une méthode à étapes multiples au moyen des critères de la International Headache Society (IHS). Ceux qui satisfaisaient aux critères de la migraine ont ensuite été évalués au moyen du questionnaire Migraine Disability Assessment pour déterminer le niveau d'invalidité résultant de la migraine dans les trois mois précédant l'étude. Nous avons également obtenu des renseignements sur l'utilisation de médicaments destinés à prévenir ou à faire avorter les crises. Résumé : Parmi les 1513 répondants, 145 satisfaisaient aux critères de l'IHS pour le diagnostic de la migraine, soit une prévalence à vie de $9,6 \%(10,3 \%$ pour les femmes et $8,9 \%$ pour les hommes, p < 0,05). L'invalidité associée à la migraine était peu importante ou inexistante chez $53,1 \%$ (55,2\% pour les hommes et 51,3\% pour les femmes, p < 0,05), légère chez 10,3\% (11,9\% pour les hommes et $9,0 \%$ pour les femmes, $\mathrm{p}<0,05)$, modérée chez $20,7 \%$ (20,9\% pour les hommes et $20,5 \%$ pour les femmes, $\mathrm{p}<0,05)$ et sévère chez $15,9 \%(11,9 \%$ pour les hommes et $19,2 \%$ pour les femmes, $\mathrm{p}<0,05)$. Malgré le fait que $53(36,6 \%)$ des migraineux avaient une invalidité modérée ou sévère, seulement 19 sur $53(35,8 \%)$ ont rapporté qu'ils prenaient un traitement préventif et aucun n'avait utilisé un triptan. Conclusion : La prévalence de la migraine chez nos répondants est dans l'écart rapporté dans des études similaires chez les étudiants universitaires ailleurs qu'en Afrique. Malgré une invalidité élevée associée à la maladie, l'utilisation de traitements préventifs et abortifs efficaces est peu répandue.

Can. J. Neurol. Sci. 2009; 36: 216-221

Migraine is a chronic episodic disorder that is associated with a significant disability in the sufferers. It is rated by the World Health Organization as one of the most disabling chronic disorders, along with quadriplegia, dementia and psychosis ${ }^{1}$. A crude prevalence rate of $5.3 \%$ was reported from a communitybased study by Osuntokun et al in Nigeria ${ }^{2}$ in comparison to the one-year prevalence rate of $11 \%$ in the United States and Western Europe (6\% in men and $15-18 \%$ in women) while a population based survey among Canadian adults showed the prevalence to be $14 \%^{3-6}$. The overall prevalence in university students has been found to range from as low as $2.4 \%$ in Greece $^{7}$ to as high as $33 \%$ in Brazil $^{8}$. The associated disability in migraine is enormous and the Migraine Disability Assessment

From the Division of Neurology, Department of Medicine (KWW), University of Ilorin Teaching Hospital, Ilorin; Department of Medicine (AJU), Irrua Specialist Teaching Hospital, Irrua, Edo State, Nigeria.

Received August 25, 2008. Final Revisions Submitted November 3, 2008 Correspondence to: KW Wahab, Division of Neurology, Department of Medicine, University of Ilorin Teaching Hospital, PMB 1459, Ilorin, 240001, Kwara State, Nigeria. 
(MIDAS) score is used to define the level of associated disability in the sufferers. This questionnaire makes assessment of severity of the disease easy and also assists the clinician in the choice of abortive and preventive treatments ${ }^{9}$.

Despite the progress in the acute management and prevention of migraine, the condition still remains underdiagnosed and the available therapies are underused ${ }^{10}$. This is even worse in some parts of the world where effective abortive medications like triptans are not available. For instance, in spite of the fact that one of the triptans has been tried in a group of migraineurs in Nigeria and found to be effective ${ }^{11}$, the triptans are still not readily available.

Studies on migraine among Nigerians are few and there is no information on the number of migraineurs who seek or utilize acute therapy while the disability associated with this condition has not been studied before in the country. The objectives of this study were to determine the lifetime prevalence of migraine among the students of a Nigerian university and also determine the associated disability using the MIDAS score. This will throw some light on the prevalence of this condition in Nigeria and provide a rationale for use of abortive and preventive treatments in the sufferers so as to reduce the associated disability and improve their quality of life.

\section{METHOD}

This was a cross-sectional study carried out at the Ambrose Alli University, Ekpoma in Southern Nigeria with a student population of 6,000 and a total of nine faculties and a college as at the time of the study (January, 2007). The university has students predominantly from the south-south, south-east and south-western regions of the country. The study proforma was approved by the research and ethics committee of Irrua Specialist Teaching Hospital which is the training hospital for the university's medical school. A training of the research assistants for the study (who were fifth year medical students) on administration of the questionnaire was conducted after which a pilot study was undertaken with 30 students. The questionnaire was modified after the pilot study and it was this modified version that was used for the actual study.

To obtain the lifetime prevalence of migraine from this student population, the sample size to be studied was estimated to be 200 . This was based on a standard normal deviate of 1.96 and a degree of accuracy of 0.05 while the proportion of university students with migraine was put at $16 \%$ based on a previous study in the country ${ }^{12,13}$. However, in order to avoid the possibility of type 2 error in addressing the second objective (to determine migraine associated disability), a fairly large size of migraineurs would be needed; thus the primary sampling unit was increased to 2,000 from a sampling frame of 6,000 undergraduate students. We divided the sampling unit into ten clusters based on a total of nine faculties and a college. Each of the clusters had a total of 200 semi-structured questionnaires administered on the students using convenience sampling method based on their availability in the lecture rooms in their various departments or hostels at the time of the interview after an informed consent to participate in the study was obtained. The authors were on hand to give clarifications where necessary.

In the first phase of the study, relevant socio-demographic information was obtained while screening for migraine was done with the use of International Headache Society (IHS) criteria ${ }^{14}$. The criteria include:

A. At least five attacks fulfilling criteria B-D

B. Headache attacks lasting 4-72 hours (untreated or unsuccessfully treated)

C. Headache has at least two of the following characteristics:

1. Unilateral location

2. Pulsating quality

3. Moderate or severe pain intensity

4. Aggravation by or causing avoidance of routine physical activity (e.g. walking or climbing stairs)

D. During headache at least one of the following:

1. Nausea and/or vomiting

2. Photophobia and phonophobia

E. Not attributed to another disorder

Presence of aura was not assessed. Other information obtained include precipitants of acute attack, and drugs used in prevention and treatment. Preventive drugs were taken to be those used by the respondents on a daily basis for most of the time with a view to preventing an acute attack; this could be prescribed by physicians or self-prescribed while drugs used for treatment were taken to be those used by the migraineurs to abort an acute attack.

Table 1: Overall and sex prevalence of migraine among respondents

\begin{tabular}{|c|c|c|c|}
\hline Migraine & Overall, n(\%) [95\% CI] & Male, $n(\%)[95 \%$ CI] & Female, $n(\%)[95 \% \mathrm{CI}]$ \\
\hline Absent & 1368 (90.4) [88.9-91.9] & $688(91.1)$ [89.0-93.2] & 680 (89.7) [87.5-91.9] \\
\hline Present & 145 (9.6) [8.1-11.1] & $67(8.9)$ [6.9-10.9] & $78(10.3)[8.1-12.5]$ \\
\hline Total & $1513(100.0)$ & $755(100.0)$ & $758(100.0)$ \\
\hline
\end{tabular}

$\mathrm{CI}=$ confidence interval 
Table 2: Demographic and clinical characteristics of the migraineurs

\begin{tabular}{lcccc}
\hline Variable & Overall $(\mathbf{n = 1 4 5})$ & Male $(\mathbf{A})(\mathbf{n = 6 7})$ & Female $(\mathbf{B})(\mathbf{n = 7 8})$ & $\begin{array}{c}\text { p value } \\
\text { A vs B }\end{array}$ \\
Age, years & $22.0 \pm 3.3$ & $22.0 \pm 3.3$ & $22.4 \pm 3.3$ & 0.47 \\
Age at onset, years & $17.3 \pm 4.2$ & $17.3 \pm 4.3$ & $17.5 \pm 3.5$ & 0.76 \\
Duration, years & $5.1 \pm 3.7$ & $5.0 \pm 3.7$ & $5.1 \pm 3.7$ & 0.87 \\
Family history & $47(32.4)$ & $21(31.3)$ & $26(33.3)$ & 0.80 \\
Number of attacks in the previous 3 months & $5.0 \pm 7.7$ & $5.3 \pm 8.6$ & $4.8 \pm 6.9$ & 0.70 \\
Mean pain intensity & $4.7 \pm 4.1$ & $4.2 \pm 4.0$ & $5.2 \pm 4.0$ & 0.14 \\
Use of preventive treatment & $37(25.5)$ & $18(26.9)$ & $19(24.4)$ & 0.73 \\
\hline
\end{tabular}

Values are mean \pm SD and frequency (percentage)

In the second phase, associated disability in the three months preceding the study was assessed in those who satisfied the IHS criteria for migraine with the aid of MIDAS questionnaire ${ }^{15}$. A score of 0-5 was graded as little or no disability (grade I), 6-10 as mild disability (grade II), 11-20 as moderate disability (grade III) while $>20$ was defined as severe disability (grade IV). Questions were answered on the number of days of headache in the three months before the study while intensity of headache was assessed on a scale of $0-10$ in which 0 represented no pain at all and 10 represented pain as bad as it could be.

\section{Statistics}

Statistical analysis was done with the Statistical Package for the Social Sciences version 11.0 (SPSS Inc). Frequency tables with appropriate 95\% confidence limits for the variables of interest were generated while means and standard deviations were calculated. For comparison of the difference between categorical variables, Chi-square test was used while means were compared using analysis of variance (ANOVA). A p value $<0.05$ was taken as a measure of statistical significance.

\section{Results}

\section{Characteristics of the respondents and prevalence of migraine}

Out of the 2,000 questionnaires distributed, only 1,513 were returned with complete information giving a response rate of $75.7 \%$. There was no statistically significant gender difference in the non-responders ( 230 males and 257 females, $\mathrm{p}=0.12)$. The responders comprised of 755 males and 758 females with a mean

Table 3: Migraine disability by gender and in relation to use of preventive treatment

\begin{tabular}{lccccc}
\hline MIDAS score & Overall $(\mathbf{n = 1 4 5})$ & Males $(\mathbf{A})(\mathbf{n = 6 7})$ & Females $(\mathbf{B})(\mathbf{n = 7 8})$ & $\begin{array}{c}\text { Use of Preventive } \\
\text { Treatment }(\mathbf{n}=\mathbf{3 7})\end{array}$ & $\begin{array}{c}\text { p value } \\
\text { A vs B }\end{array}$ \\
Grade I & & & $40(51.3)$ & $15(40.5)$ & 0.64 \\
& $77(53.1)$ & $37(55.2)$ & {$[40.0-62.6]$} & {$[24.4-56.6]$} & \\
Grade II & {$[44.8-61.3]$} & {$[43.1-67.4]$} & $7(9.0)$ & $3(8.1)$ & 0.56 \\
& $15(10.3)$ & $8(11.9)$ & {$[2.5-15.5]$} & {$[-0.9-17.1]$} & \\
Grade III & {$[5.3-15.3]$} & {$[4.0-19.8]$} & $16(20.5)$ & $11(29.7)$ & 0.95 \\
& $30(20.7)$ & $14(20.9)$ & {$[11.4-29.6]$} & {$[14.7-44.7]$} & 0.23 \\
Grade IV & {$[14.0-27.4]$} & {$[11.0-30.8]$} & $15(19.2)$ & $8(21.6)$ & 0.23 \\
& $23(15.9)$ & $8(11.9)$ & {$[10.3-28.1]$} & {$[8.1-35.1]$} & \\
\hline
\end{tabular}

Values are frequency (percentage) [95\% Confidence interval] 
Table 4: Treatment and preventive options of all migraineurs

\section{Treatment option}

Frequency

$\%[95 \% \mathrm{CI}]$

\section{Preventive treatment}

\begin{tabular}{lcc} 
Paracetamol & 25 & $67.6[52.2-83.0]$ \\
NSAID & 6 & $16.2[4.1-28.3]$ \\
Unspecified & 6 & $16.2[4.1-28.3]$ \\
Treatment of acute attack & & \\
Paracetamol & 86 & $59.3[57.9-60.7]$ \\
NSAID & 8 & $5.5[1.7-9.3]$ \\
Rest alone & 9 & $6.2[2.2-10.2]$ \\
Cafergot (ergotamine preparation) & 4 & $2.8[0.1-5.5]$ \\
Antimalarial & 4 & $2.8[0.1-5.5]$ \\
NSAID + sedative & 2 & $1.4[-0.6-3.4]$ \\
Opiate & 1 & $0.7[-0.7-2.1]$ \\
Triptan & 0 & $0.0[0.0-0.0]$ \\
Unspecified & 31 & $21.4[14.6-28.2]$ \\
\hline
\end{tabular}

NSAID=Non-steroidal anti-inflammatory drug, $\mathrm{CI}=$ confidence interval

age of $23.3 \pm 2.5$ years; of this number, $488(32.3 \%)$ with a mean age of $22.3 \pm 3.2$ years had recurrent headaches. The mean age of those without recurrent headache was $22.4 \pm 3.4$ years $(\mathrm{p}=$ 0.58). Out of those with recurrent headache, $145(29.9 \%)$ satisfied the IHS criteria for the diagnosis of migraine giving an overall frequency of $145 / 1513$ i.e. $9.6 \%$ (95\% CI $=8.1 \%$ $11.1 \%)$. The overall and sex prevalence of migraine is given in Table 1 which shows that females have a higher prevalence of $10.3 \%(95 \% \mathrm{CI}=8.1 \%-12.5 \%)$ compared to $8.9 \%(95 \% \mathrm{CI}=$ $6.9 \%-10.9 \%$ ) in male respondents though this was not statistically significant $(\mathrm{p}=0.35)$.

\section{Characteristics of the migraineurs}

As shown in Table 2, the mean age of all migraineurs was $22.0 \pm 3.3$ years and there was no significant gender difference in the characteristics. There was a positive family history of migraine in a first degree relation in $32.4 \%$ while the overall mean pain intensity in the three months before the study was 4.7 with females having a higher score of 5.2 compared to 4.2 in males ( $\mathrm{p}>0.05)$.

\section{Migraine associated disability}

Table 3 shows that migraine disability was grade I (little or no disability) in $53.1 \%$ (95\% CI= 44.8\%-61.3\%) while $15.9 \%(95 \%$ $\mathrm{CI}=9.8 \%-22.0 \%$ ) were in group IV (severe disability). In all, $36.6 \%(95 \% \mathrm{CI}=28.6 \%-44.6 \%)$ had moderate-severe disability but in spite of this, only $35.8 \%(95 \% \mathrm{CI}=22.6 \%-49.0 \%))$ of the
53 respondents with this degree of disability reported being on preventive treatments.

\section{Use of preventive and abortive therapies}

In Table 4, a further analysis of the type of preventive and abortive treatments used by all migraineurs was assessed and this shows that for prevention, $67.6 \%$ of them use paracetamol while $16.2 \%$ use non-steroidal anti-inflammatory drugs (NSAIDs) and a further $16.2 \%$ did not specify the type of medications they use for prevention. In the treatment of acute attack, majority of the sufferers $(64.8 \%)$ use only simple analgesics (paracetamol and NSAID), $2.8 \%$ use ergot containing preparations while none reported having ever used triptans.

\section{DisCuSSION}

This cross-sectional study has shown that the lifetime prevalence of migraine among Nigerian University students is 9.6\% with a slightly higher prevalence in females compared to males $(10.3 \%$ vs $8.9 \%)$ though this is not statistically significant. The age at onset is in the latter second decade in both sexes while about $37 \%$ of the sufferers have moderate to severe disability on the MIDAS score.

The prevalence obtained in this study falls within the range of $2.4 \%$ to $33 \%$ that has been reported from similar studies among university students ${ }^{7,8}$. The observed sex prevalence and the confidence intervals are also similar to the sex prevalence of $7.8 \%$ and $8 \%$ reported for males and females respectively among Qatari adults in a population-based study ${ }^{16}$. While the overall prevalence is lower than the $12.2 \%$ reported by Deleu et $\mathrm{al}^{17}$ in a similar descriptive epidemiological study on medical students in Oman and the $12.4 \%$ reported by Demirkirkan et al ${ }^{18}$, the male prevalence rate is the same as the $8.9 \%$ reported in the latter study. These two studies ${ }^{17,18}$ also reported higher prevalence rates of $14 \%$ and $15.5 \%$ respectively in females, while a range of $15-18 \%$ has been reported in women in Western Europe and United States ${ }^{3-5}$. Similarly, the prevalence among males in this study is comparable to the $7.8 \%$ reported among Canadian males in a population-based study while the prevalence among females is about half of the $24.9 \%$ that was reported from that study ${ }^{19}$, though the overall prevalence is lower than that reported by Pryse-Phillips et $\mathrm{al}^{6}$. The observed low prevalence among our female respondents could possibly be because of poor recall of the symptoms of the disease or that those with migraine do not get admission to the university because of the disease compared to their male counterparts.

When compared to a similar cross-sectional study among university students in Nigeria more than two decades ago, the prevalence is lower as that study reported a prevalence of $16 \%$ for migraine ${ }^{13}$. That study could however have possibly overestimated the prevalence because the Ad Hoc Committee report on headache classification published in $1964^{20}$ was utilized in making an assessment of migraine after validation by a clinical diagnosis whereas the current edition of the IHS criteria was used in our study. Our prevalence is also higher than the $5.3 \%$ crude prevalence reported by Osuntokun et $\mathrm{al}^{2}$ in a communitybased study but this is not unexpected as migraine incidence is high in the third decade of life and the mean age of our respondents is 23.3 years. The latter study was also not strictly 
based on IHS criteria but rather utilized a questionnaire validated by neurological examination and this could have possibly been more sensitive in detecting those without migraine than our own screening which was purely questionnaire-based.

Although the MIDAS questionnaire is useful in recommending treatment and preventive therapies for migraineurs $^{9}$ and also facilitates communication between physicians in addition to making studies comparable, we are not aware of any study that has utilized it in the evaluation of migraine in a standardized manner in Nigeria. Among our respondents, we found that the migraine associated disability was grade I in $53.1 \%$, grade II in $10.3 \%$ and grade III in $20.7 \%$, while $15.9 \%$ had grade IV disability. The migraineurs with moderate-severe disability in this study is low (36.6\%) when compared to the range of $47 \%$ to $56 \%$ reported for those with grade III or IV disability in the international Migraine and Zolmitriptan Evaluation study ${ }^{21}$ and the $77.8 \%$ reported for those with moderate-severe disability in the study of Jelinski et al in which the clinical features and pharmacologic management of migraineurs referred to headache specialists in Canada was reviewed $^{22}$. However, the high disability in the latter study could have been over-represented because it is very likely that it was the patients with worse headaches that were referred to the neurologists for expert management. The degree of disability is also low when compared to the findings from a similar study in Turkey in which it is reported that $67.9 \%$ of their respondents had moderate-severe disability ${ }^{18}$. The reasons for this low disability could possibly be because the mean number of attacks per month in the latter study is five compared to a mean of five attacks in the previous three months in our study. It is also possible that our respondents were not able to recall the disturbances from all the attacks they had in the three months prior to the study or that they were still able to function in spite of the headache. If the latter situation applies, then they are likely to have under-reported the disability associated with the disease. It is also important to note that the social perception of the person with recurrent headaches could have influenced the reported disability in this study because in many cultures in Nigeria, recurrent inability to work or do household chores as a result of headaches is socially perceived as a form of malingering.

Out of the $53(36.6 \%)$ migraineurs with disability in the moderate to severe range (grade III-IV), only 19 (35.8\%) reported using preventive medications. A further analysis however showed that the preventive medications they mentioned were just simple analgesics like paracetamol and non-steroidal anti-inflammatory drugs like diclofenac and ibuprofen. None of the sufferers used any of the well-documented preventive drugs like amitriptylline. Also, none of the sufferers reported having ever used triptans and only $2.8 \%$ use oral ergot containing preparations to abort an attack. Our finding on the latter drug is in consonance with the report of Lipton and Silberstein that only $5 \%$ and $10 \%$ of migraineurs use ergot and triptans respectively to abort their attacks ${ }^{10}$. However, since triptans were not readily available and only oral ergotamine preparations are seen in most pharmacies in the country, it is probable that their poor use is as a result of unavailability rather than under-utilization. Nonetheless, we suggest that there should be more public health education on migraine and that the effective preventive and abortive therapies should be made available so that the sufferers can access them and have improved quality of life.

The main strength of this study is the fact that in addition to determining the prevalence of migraine among university students in Nigeria, it has also studied the associated disability in the sufferers. To the best of our knowledge, this is the first time the MIDAS questionnaire was used in the systematic evaluation of disability among migraineurs in Nigeria although we appreciate that the study was limited by a number of factors. Firstly, since a great majority of students in Nigerian universities are from average income homes, the observed prevalence in them might not be a true reflection of the situation in the country because of association of migraine with low socioeconomic status $^{3}$. In addition, the study could have been influenced by recall bias because it is possible that some of the students did not readily recall if they had any of the symptoms screened for while some of them might not know the actual names of the drugs they use either for prevention or treatment of acute attacks. We however believe that the objectives were largely achieved, though a community-based study will be needed to validate our findings.

\section{ACKNOWLEDGEMENTS}

We acknowledge the co-operation of the authorities and students of Ambrose Alli University, Ekpoma in allowing this study. We are also grateful to our students: Ayodeji Owolabi, Samuel Eseile and Terry Kenu who served as our research assistants.

\section{REFERENCES}

1. Menken M, Munsat TL, Toole JF. The global burden of disease study implications for neurology. Arch Neurol. 2000; 57: 418-20.

2. Osuntokun BO, Adeuja AO, Nottidge VA, Bademosi O, Alumide AO, Ige $\mathrm{O}$, et al. Prevalence of headache and migrainous headache among Nigerian Africans: a community-based study. East Afr Med J. 1992; 69(4): 196-9.

3. Stewart WF, Lipton RB, Celentano DD, Reed MI. Prevalence of migraine headache in the United States: relation to age, income, race and other sociodemographic factors. JAMA. 1992; 267: 64-9.

4. Rasmussen BK, Olesen J. Symptomatic and nonsymptomatic headaches in a general population. Neurology. 1992; 42: 1225-31.

5. Steiner TJ, Stewart WF, Kolodner K, Liberman J, Lipton RB. Epidemiology of migraine in England. Cephalalgia. 1999; 19: 3305-6. [abstract].

6. Pryse-Phillips W, Findlay H, Tugwell P, Edmeads J, Murray TJ, Nelson RF. A Canadian population survey on the clinical, epidemiologic and societal impact of migraine and tension-type headache. Can J Neurol Sci. 1992; 19 (3): 333-9.

7. Mitsikostas DD, Gatzonis S, Thomas A, Kalfakis N, Ilias A, Papageoergiou C. An epidemiological study of headaches among medical students in Athens. Headache. 1996; 36: 561-4.

8. Sanvito WL, Monzillo PH, Peres MF, Martinelli MO, Fera MP, Gouveia DA, et al. The epidemiology of migraine in medical students. Headache. 1996; 36: 316-9.

9. Lipton RB, Stewart WF, Stone AM, Lainez MJA, Sawyer JPC. Stratified care versus step care strategies for migraine. JAMA. 2000; 284: 2599-605.

10. Lipton RB, Silberstein SD. The role of headache-related disability in migraine management: implications for headache treatment guidelines. Neurology. 2001; 56: 35-42.

11. Oluwole S, Bwala SA, Nwabueze AC, Davies AO. Effectiveness of sumatriptan for acute treatment of migraine headache in an African population. Afr J Neurol Sci. 2003; 22(2). Available from: http://www.ajol.info. [cited 2008 Jan 7]. 
12. World Health Organization Teaching Statistics. In: Lwanga SK, Tye CY, editors. Twenty lessons and seminar outlines. Geneva WHO. 1986. p. 67-74

13. Ogunyemi AO. Prevalence of headache among Nigerian university students. Headache. 1984; 24: 127-30.

14. Headache Classification Committee of the International Headache Society. The international classification of headache disorders. (2nd ed.). Cephalalgia. 2004; 24 suppl 1: 1-160.

15. Stewart WF, Lipton RB, Kolodner K, Liberman J, Sawyer J. Reliability of the Migraine Disability Assessment score in a population-based sample of headache sufferers. Cephalalgia. 1999; 19: 107-14.

16. Bener A. Frequency of headache and migraine in Qatar. Neuroepidemiology. 2006; 27(2): 61-6.

17. Deleu D, Khan MA, Humaidan H, Al Mantheri Z, Al Hashami S. Prevalence and clinical characteristics of headache in medical students in Oman. Headache. 2001; 41 (8): 798-804.
18. Demirkirkan MK, Ellidokuz H, Boluk A. Prevalence and clinical characteristics of migraine in university students in Turkey. Tohoku J Exp Med. 2006; 208: 87-92.

19. O'Brien B, Goeree R, Streiner D. Prevalence of migraine headache in Canada: a population-based survey. Int J Epidemiol. 1994; 23 (5): 1020-6.

20. Ad Hoc Committee: Classification of Headache. JAMA. 1962; 179: 717-18.

21. MacGregor EA, Brandes J, Eikermann A. Migraine prevalence and treatment patterns: the global migraine and zolmitriptan evaluation survey. Headache. 2003; 43: 19-26.

22. Jelinski SE, Becker WJ, Christie SN, Giammarco R, Mackie GF, Gawel MJ, et al. Clinical features and pharmacological treatment of migraine patients referred to headache specialists in Canada. Cephalalgia. 2005; 26: 578-88. 